\title{
A Model Study of the Continuous Casting of Steel Slab*
}

\author{
By Ken-ichi MIYAZAWA $A^{* *}$ and Iwao MUCHI**
}

\section{Synopsis}

A simulation study of the continuous casting of steel slab has been made by using the aqueous solution of potassium chloride. Solidification profiles from the meniscus to the bottom of a mushy zone, the region of forced convection caused by the inlet stream, and the temperature distributions in the slab have been observed under the various casting speeds by the use of a straight nozzle and a bifurcated nozzle.

Exprrimental results show some differences between the profiles of liquidus line in the region of forced convection obtained by use of the straight nozzle and the bifurcated nozzle. This difference in the profiles is interpreted from the different flow patterns and the different temperature distributions in a liquid pool.

Furthermore, it has been found that the difference in the profiles of solidus line for each run is almost negligibly small and that the primary dendrite arm spacings in the region affected by the forced convection are different between the runs made by using both nozzles.

Solidification profiles obtained in these experiments are compared with the profiles predicted by the mathematical model which was previously presented by the authors.

\section{Introduction}

Several mathematical models ${ }^{1-3)}$ have been presented hitherto to estimate the solidification profiles in the continuous castings of steel. However, their validity has not fully investigated. For that purpose, the operating data of the solidification profiles from the meniscus to the end point of solidification and also the cooling conditions on the surface of casting are required.

The solidification profiles in the continuous casting of steel are measured by the so-called run-out method, ${ }^{4,5)}$ the tracer technique ${ }^{6)}$ using radioactive isotopes and the rivet pin shooting technique. ${ }^{7)}$ However, the thickness of the mushy zone can not be determined from the data obtained by the use of the run-out method or the tracer technique. Furthermore, it is known that in the neighborhood of the bottom of mushy zone the data obtained by the rivet pin shooting technique are somewhat inaccurate.

In the fields of study on the morphology of crystal grow $\mathrm{th}^{8-11)}$ and the rate of movement of the macroscopic solid-liquid interface, ${ }^{12,13}$ ) the model experiments of solidification have been conducted by the use of a transparent-aqueous solution. Moreover, model experiments are used to explain the formation of equiaxed crystals and the macrosegregation in steel ingots. ${ }^{14-19)}$

However, the most of the reported model experiments for the continuous casting of steel were the water model studies without freezing.

Using the water-ice system, Mills and Barnhardt ${ }^{20)}$ investigated on the most suitable nozzle type for the fluid flow to prevent the break-out and to promote the floating of non-metallic inclusions. Watanabe, et al. ${ }^{21}$ studied the heat transfer process from the liquid pool to the cooling water in the mold from the solidification of paraffin.

In the present study, the model experiments for the continuous casting of slab have been made by the use of KCl solution as a solidification system. The effects of the operating conditions such as the casting speed and the nozzle type on the solidification profiles and the casting structure are examined in this paper.

Furthermore, the results calculated from the mathematical model ${ }^{2}$ for the continuous castings of steel presented by the authors are compared with the experimental results. The similarity of heat transfer is discussed between the experiments in this work and the practical continuous castings of steel.

\section{Experimental Method}

\section{Procedure of Model Experiments}

Schematic view of the experimental apparatus used in this study is shown in Fig. 1 (a) and (b) and the experimental conditions are given in Table 1.

The ethyl alcohol in two cooling boxes was cooled to a given temperature by dry ice. Aqueous solution of potassium chloride was kept at a constant temperature in the cylindrical tank. It was poured into the mold from a nozzle through a siphon. By this siphon, the fluid flow in the liquid pool was stabilized by reducing the fluctuation due to the change in the flow rate. According to the rise of the meniscus in the mold, the nozzle was pulled up by a motor. The bifurcated nozzle given in Table 1 is made of copper pipe. Its two lateral apertures with diameter $4 \mathrm{~mm}$ are at right angles to the axis of copper pipe.

After the steady state progress of the solidification front was confirmed, the solidification profiles were observed through the transparent plate made of vinyl chloride. The changes in temperature were measured by the use of six copper-constantan thermocouples. Their junctions were positioned at the distances of $1,3,6,9,12$ and $15 \mathrm{~mm}$ from the inner surface of the mold. Their horizontal positions were at 25, 26, 27, 28, 29 and $30 \mathrm{~cm}$ from the bottom. The fluid flow in the region of forced convection due to the input stream was observed by injecting a

* Originally published in Tetsu-to-Hagané, 62 (1976), 210, in Japanese. English version received March 8, 1976.

** Department of Iron and Steel Engineering, Nagoya University, Furo-chō, Chikusa-ku, Nagoya 464. 


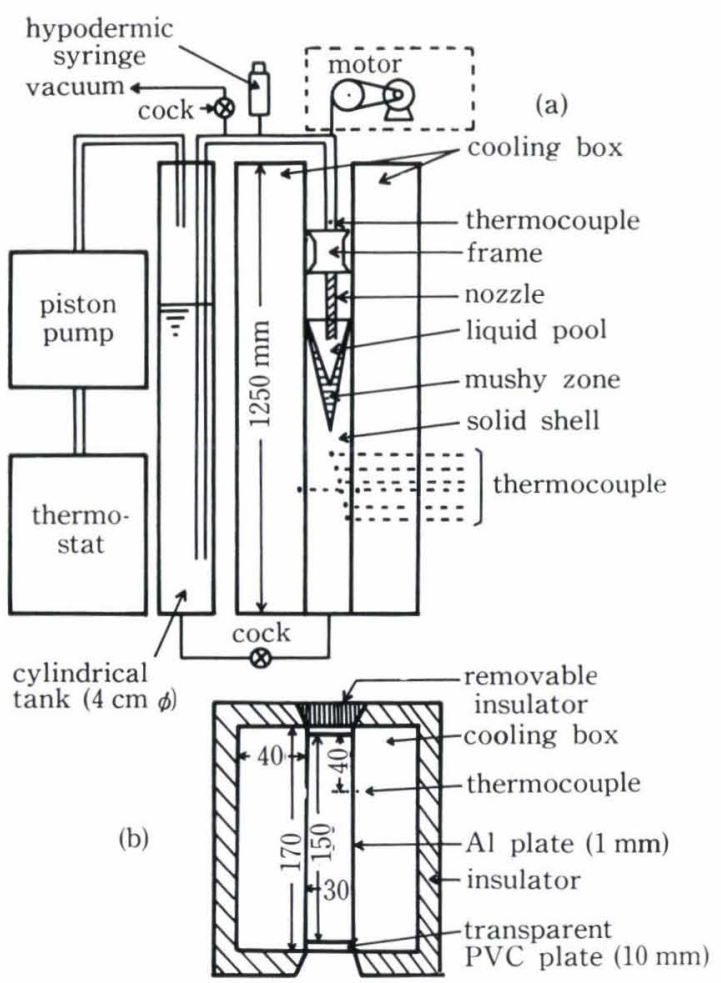

(a) Assembly of apparatus

(b) Cross section of mold

Fig. 1. Schematic representations of apparatus

Table 1. Experimental conditions

Concentration of $\mathrm{KCl}$ solution: $1 \mathrm{~mol} / \mathrm{l}$

Slab size: $3 \times 15 \mathrm{~cm}$

Type of submerged nozzle: Straight ( $7 \mathrm{~mm} \dot{)})$ Bifurcated (4 mmo

Casting speed: $3 \sim 7 \mathrm{~cm} / \mathrm{min}$

Teeming temperature: $6^{\circ} \mathrm{C}$

Temperature in cooling box : $-58^{\circ} \sim-62^{\circ} \mathrm{C}$

Room temperature: $5^{\circ} \sim 10^{\circ} \mathrm{C}$

tracer (black ink) into the siphon by using a hypodermic syringe.

\section{Solidification of Aqueous Solution of $\mathrm{KCl}$ and Estima- tion of Latent Heat of Solidification}

Phase diagram for the $\mathrm{KCl}-\mathrm{H}_{2} \mathrm{O}$ system is shown in Fig. 2. It was constructed from the data reported by the other investigators. ${ }^{22,23)}$ From Fig. 2, the equilibrium distribution coefficient of $\mathrm{KCl}$ in the range of concentration from 0 to $3.3 \mathrm{~mol} / l$ is equal to zero. Thus, during the progress of solidification the mushy zone consists of the dendrites of ice and the enriched solution of $\mathrm{KCl}$. At the eutectic point, the liquid $\mathrm{KCl}-\mathrm{H}_{2} \mathrm{O}$ system of the eutectic composition turns to the cryohydrate ${ }^{23)}$ consisting of the crystals of $\mathrm{KCl}$ and those of ice. Thus, by taking account of the latent heat of solidification of water $\left(\Delta H_{\mathrm{w}}\right)$ and of the aqueous solution of $\mathrm{KCl}$ of the eutectic concentration $\left(\Delta H_{\mathrm{e}}\right)$, the latent heat $(\lambda)$ to be generated in the solidification of the solution of $\mathrm{KCl}$ of the initial concentration $\left(C_{0}\right)$ is approximately given as follows:

$$
\lambda=\Delta H_{\mathrm{w}} \cdot\left(C_{\mathrm{e}}-C_{0}\right) / C_{\mathrm{e}}+\Delta H_{\mathrm{e}} \cdot C_{0} / C_{\mathrm{e}}
$$

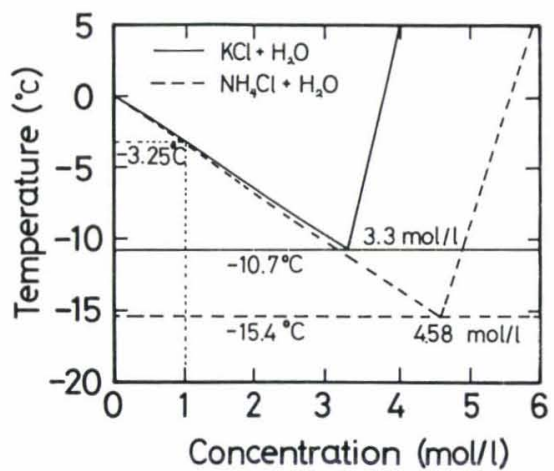

Fig. 2. Phase diagram for $\mathrm{KCl}-\mathrm{H}_{2} \mathrm{O}$ and $\mathrm{NH}_{4} \mathrm{Cl}-\mathrm{H}_{2} \mathrm{O}$ systems

where, $C_{\mathrm{e}}$ designates the eutectic concentration. In the case of the solidification of the solution of $\mathrm{KCl}$ at the concentrations above $3.3 \mathrm{~mol} / l$, the mushy zone consists of the crystals of $\mathrm{KCl}$ and the diluted solution of $\mathrm{KCl}$. By taking account of $\Delta H_{\mathrm{e}}$ and the heat of crystallization of $\mathrm{KCl}\left(\Delta H_{\mathrm{c}}\right)$, the latent heat to be generated in this case can be given as follows:

$$
\lambda=\left\{\Delta H_{\mathrm{c}} \cdot\left(C_{0}-C_{\mathrm{e}}\right)+\Delta H_{\mathrm{e}} \cdot\left(100-C_{0}\right)\right\} /\left(100-C_{\mathrm{e}}\right) .
$$

In Fig. 2, phase diagram for the $\mathrm{NH}_{4} \mathrm{Cl}-\mathrm{H}_{2} \mathrm{O}$ system reported by the other investigators ${ }^{22}$ is also shown. The solution of $\mathrm{NH}_{4} \mathrm{Cl}$ has been used by several investigators ${ }^{14-19)}$ to explain the solidification phenomena such as the formation of the equiaxed crystals and the macrosegregation in the conventional steel ingots. However, the concentrations were above $4.58 \mathrm{~mol} / l$ and thus the solid phase in the mushy zone is the dendritic crystals of $\mathrm{NH}_{4} \mathrm{Cl}$. Comparing the solidification of the $\mathrm{NH}_{4} \mathrm{Cl}-\mathrm{H}_{2} \mathrm{O}$ system above the eutectic concentration with that of the steel, $\mathrm{NH}_{4} \mathrm{Cl}$ corresponds to $\mathrm{Fe}$. Contrarily, in the case of the solidification of the solution of $\mathrm{KCl}$ at $1 \mathrm{~mol} / l$ used in this work, $\mathrm{H}_{2} \mathrm{O}$ corresponds to $\mathrm{Fe}$.

\section{Results and Discussions}

\section{Experimental Results}

Photograph 1 illustrates the solidification profiles observed in this work. In Photo. 1, the liquid pool corresponds to the black part. With the naked eye, the solid shell appears white, the mushy zone is semitransparent and the liquid pool is transparent. The boundary between the solid shell and the mushy zone was visible clearly, and its line was regarded as a solidus line, and a liquidus line was considered at the location of the dendrite tips of ice.

At the beginning of the casting run, the solidification profiles proceed under the unsteady state, but with the rise of meniscus in the mold, their progress shifts gradually to the steady state. In the lower part of liquid pool, the transition from the unsteady state to the steady one was slower than that in its upper part. The freezing became steady state, when the end point of solidus line reached to the distance, 20 to $30 \mathrm{~cm}$, from the bottom of the apparatus with the rising speed of less than $6 \mathrm{~cm} / \mathrm{min}$. 

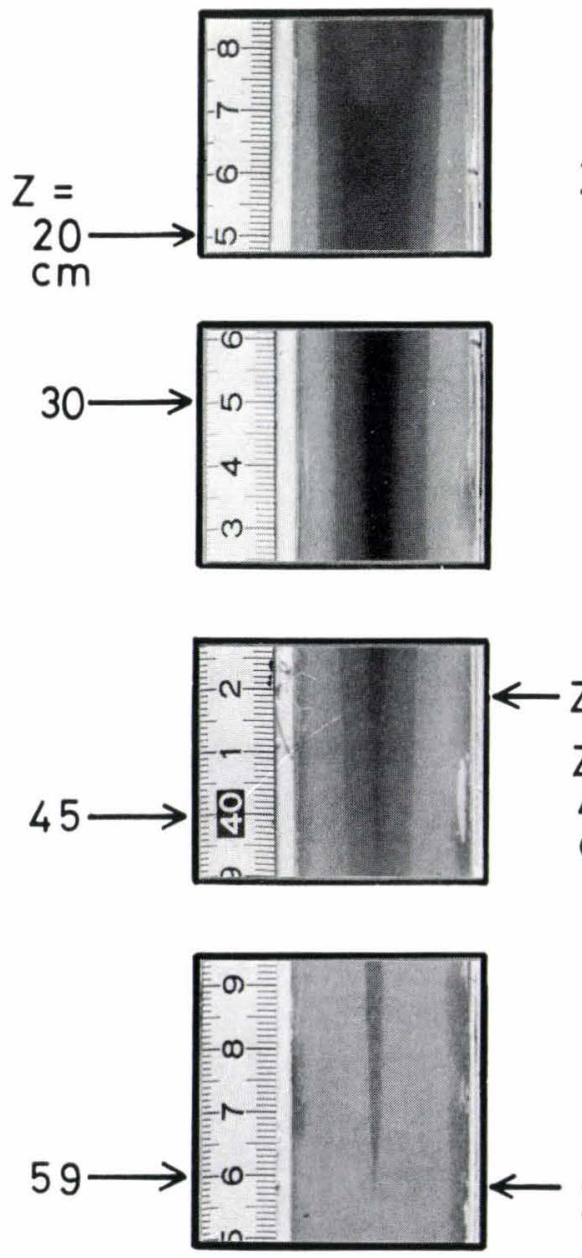

(a)

The locations of the solidus and liquidus lines observed by the use of the straight nozzle are shown in Fig. 3 for various casting speeds. The solidification profiles are affected considerably by the casting speed. At the last stage of the freezing, the progress of the solidus lines is accelerated.

At the end of these experiments, black ink was injected into the nozzle as a tracer, and in Fig. 3 the observed depths of its penetration in the liquid pool are shown with the arrows. The inlet stream mixed with black ink is decelerated rapidly after flowing into the pool. The depth of penetration of the colored stream could be measured within a fairly short time. It may be considered that this depth is equivalent to the lower limit of the region of forced convection caused by the inlet stream. In the region of forced convection, the solution of $\mathrm{KCl}$ changes color into black within 10 to $15 \mathrm{sec}$ after the tracer was fed through the exit of nozzle. After that, even if the meniscus is raised, the lower limit of that region is kept almost unchanged. However, it can be observed that on account of the natural convection the colored liquid flows down very slowly along both solidification fronts.

To examine the effects of the nozzle diameter on the solidification profiles, the experiments have been made under the constant casting speed by using the
$\mathrm{Z}_{l}$ : End of liquidus line

$\mathrm{Z}_{s}$ : $\quad$ End of solidus line

(a) $u=4.8 \mathrm{~cm} / \mathrm{min}$

(b) $u=3.6 \mathrm{~cm} / \mathrm{min}$
Photo. 1. Solidification profiles obtained in the
casting runs performed by the use of

Photo. 1. Solidification profiles obtained in the
casting runs performed by the use of straight nozzle (b)

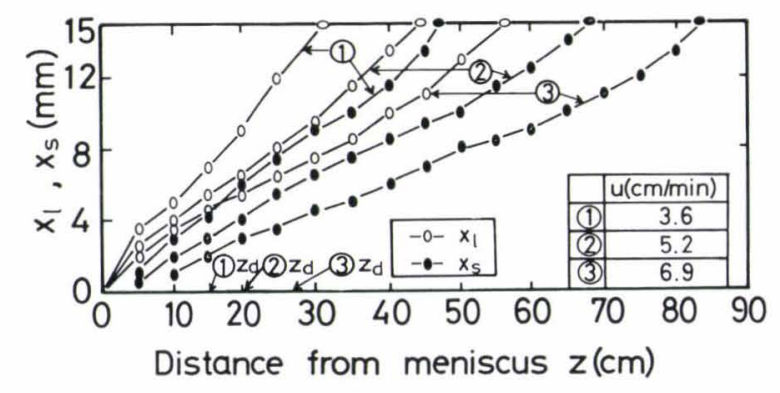

Fig. 3. Solidification profiles observed in the casting runs performed by the use of straight nozzle

straight nozzle with diameters of $3,5,7$ and $9 \mathrm{~mm} \phi$, respectively. The results obtained showed that the locations of the end point of liquidus line and of solidus line do not change very much with the nozzle diameter. However, the depth of penetration of the inlet stream becomes deeper with the smaller nozzle diameter. In the case of the nozzle of diameter $3 \mathrm{~mm} \phi$, the local hollows due to the impinging inlet stream were observed on the solidification fronts, but in the nozzle of diameter above $7 \mathrm{~mm} \phi$ the solidification fronts were almost smooth.

On the basis of the data given in Fig. 3, Fig. 4 shows the relations between the solidus and liquidus lines and the solidification time $(z / u)$. Figure 4 sug- 


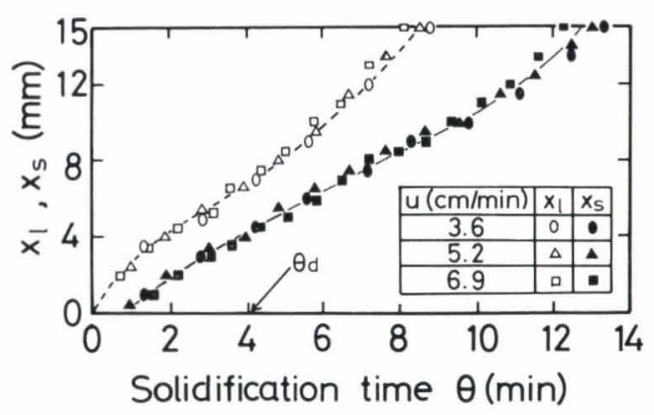

Fig. 4. Progress of the liquidus and solidus lines observed in the case of straight nozzle

gests that in these experiments the effects of the casting speed on the relation mentioned above are negligibly small. This means that the cooling conditions on the slab surface were kept constant at all parts of the mold surface. Also, the effects of the fluid flow in the liquid pool on the solidification profiles were negligible.

The solidification time corresponding to the depth of penetration of the inlet stream $\left(\theta_{d}=z_{d} / u\right)$ is also shown in Fig. 4. In these experiments, the value of $\theta_{d}$ was almost constant irrespective of the casting speed. This means that under the conditions for these experiments conducted by the use of the straight nozzle, the depths of penetration of the inlet stream are nearly proportional to the casting speeds.

Figure 5 shows the solidification profiles observed by the use of the bifurcated nozzle. It may be found from Fig. 5 that the solidus and liquidus lines are not also affected by the casting speed. However, the depths of penetration of the inlet stream in the case of the bifurcated nozzle are much smaller than those in the case of the straight nozzle. Because the value of $\theta_{d}$ is nearly 2 min regardless of the casting speed in the case of the bifurcated nozzle, the effects of the fluid flow in the liquid pool are negligible on the solidification profiles. The natural convections have been observed evidently in the liquid pool below the region of the forced convection. It took only about $5 \mathrm{sec}$ that the liquid in the region of the forced convection changed color into black. Thus, it may be considered that the degree of mixing in the region of the forced convection in the case of the bifurcated nozzle is stronger than that in the case of the straight nozzle.

The effects of the nozzle diameter on the solidification profiles have not been also recognized by the use of the bifurcated nozzle with diameter of the lateral apertures of 3,4 and $5 \mathrm{~mm} \phi$, respectively. Regardless of the nozzle diameter, the depths of penetration of the inlet stream have been almost similar to each other. The solidification fronts have been almost smooth for each case of the nozzle diameter and no local hollows have been observed on the fronts.

From the comparison of Fig. 4 with Fig. 5, it has been found that in both cases, the profiles of solidus line are almost similar but the profiles of liquidus line at the solidification time up to 4 min differ from each other. It may be considered that the temperature

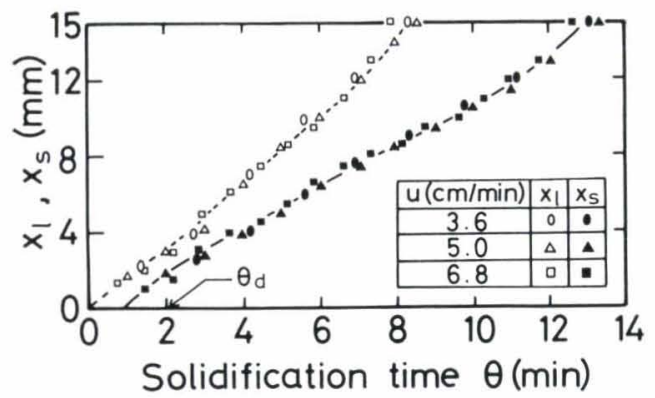

Fig. 5. Progress of the liquidus and solidus lines observed in the case of bifurcated nozzle

gradients in the liquid pool near the solidification fronts vary with the nozzle type, because the shape of nozzle opening changes the flow pattern in the liquid pool, and thus the area of the region of the forced convection, and the degree of mixing in this region. Thus, the difference in the profiles of liquidus line mentioned above will arise from the change in the temperature gradients.

In order to clarify the effects of the fluid flows caused by the different nozzle types on the solidification rate, the relations between the solidification thickness and its time are shown in Fig. 6. No difference is observed on the solidus lines for the nozzles and the profiles of the liquidus lines below the regions of the forced convection are almost similar to each other. In the abscissa of Fig. 6, the arrows show square roots of the solidification time ccrresponding to the depth of penetration of the inlet stream $\left(\sqrt{\theta_{d}}\right)$. The solidification rate constants are kept nearly constant in the following three regions, respectively: (I) the region of the forced convection caused by the inlet stream, (II) the region from the lower limit of the region (I) to the end point of liquidus line, and (III) the region between the end points of the liquidus and solidus lines. Furthermore, Fig. 6 shows that the areas of the region (I) and the distances from the slab surface to the liquidus line in the region (I) vary with the nozzle type. Regardless of the nozzle type, the solidification constants, defined by assuming that the solidification thickness is proportional to $\sqrt{ } \theta$, are almost similar to each other.

The changes in temperatures measured at various distances in the liquid from the slab surface are shown in Fig. 7 for the straight nozzle and in Fig. 8 for the bifurcated nozzle, respectively. From Figs. 7 and 8 , it may be found that the temperature distributions in the liquid vary with the nozzle type. Using the straight nozzle, the temperature near the meniscus is lower than that in the inner part of the liquid. On the other hand, using the bifurcated nozzle, the temperature near the meniscus is highest.

The differences in the temperature distributions along the distance from chill surface are clearly shown in Fig. 9 on the basis of the results shown in Figs. 7 and 8 . The solidification time used in the figure is proportional to the distances below from the meniscus. Figure 9 shows that in the levels near the meniscus (e.g., $\theta=3 \mathrm{~min}$ ), the temperature gradient in 


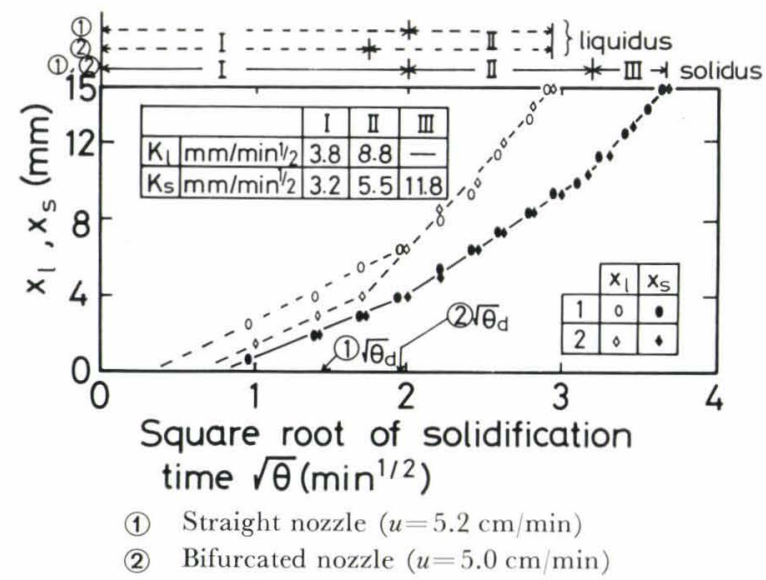

Fig. 6. Relations between the liquidus and solidus lines and the square root of solidification time

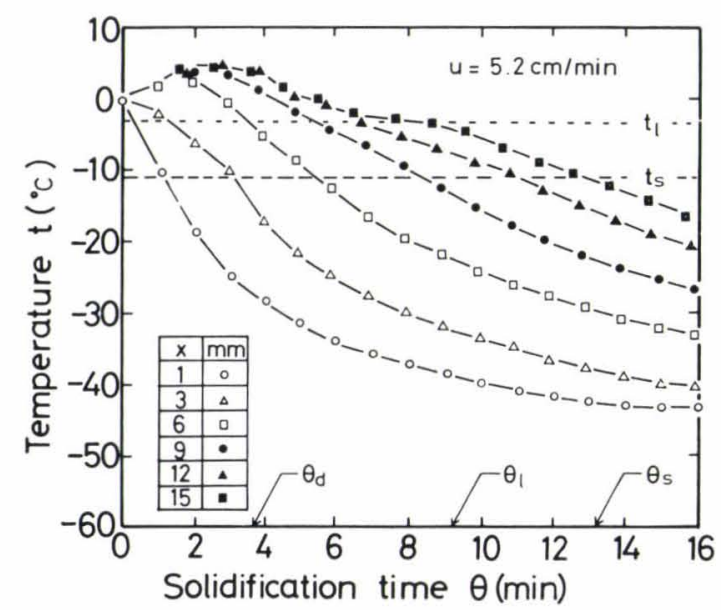

Fig. 7. Temperature change observed in the casting run performed by the use of straight nozzle

the neighborhood of the chill surface is steep and decreases with the increase in the distances from the meniscus. Contrarily, the temperature distributions observed in the solid shell and the mushy zone are nearly same for the two types of nozzles.

In these experiments, the crystal growth during freezing was dendritic over the range from the slab surface to its center. According to the empirical relationship reported by Rohatgi and Adams, ${ }^{10)}$ the primary dendrite arm spacing $\left(S_{I}[\mu]\right)$ can be expressed as a function of the local solidification time $\left(\theta_{f}[\min \rceil\right)$ from the data on the solution of $\mathrm{KCl}$ of $1 \mathrm{~mol} / l$.

$$
S_{l}=33 \sqrt{\theta_{f}}+48
$$

(The derivation of Eq. (3) is shown in Appendix.)

Figure 10 shows the local solidification time obtained from the observed solidification profiles (cf., Figs. 4 and 5) and the primary dendrite arm spacing obtained by substituting the value of $\theta_{f}$ into Eq. (3). Under these experimental conditions $S_{I}$ increases with the increase in the distances from the chill surface for both straight and bifurcated nozzles. In the region of forced convection, the values of $S_{I}$ are different for the nozzle types. Namely, the values of $S_{I}$ for the

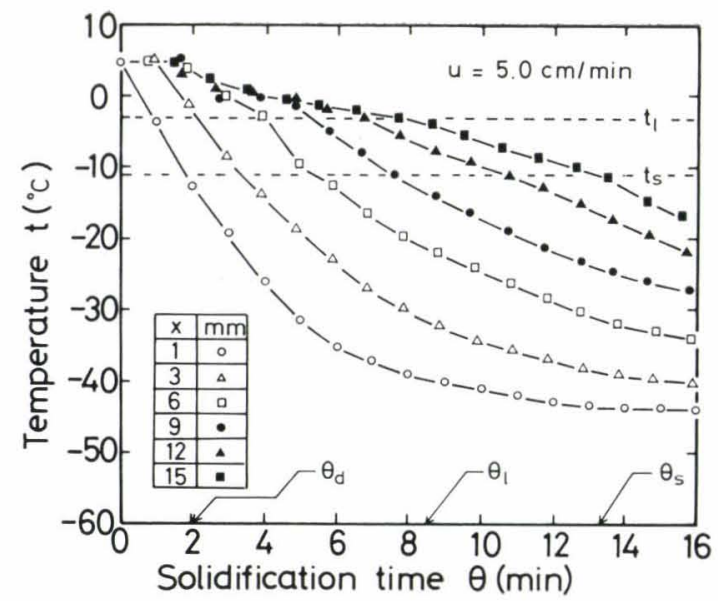

Fig. 8. Temperature change observed in the casting run performed by the use of bifurcated nozzle

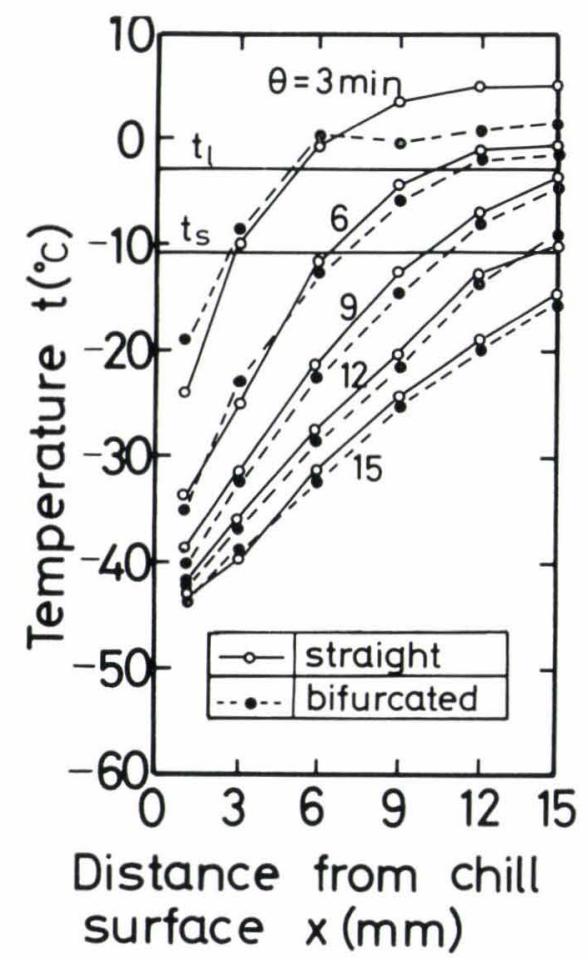

Fig. 9. Comparison of the measured temperature profiles for each run performed by the use of straight nozzle and bifurcated nozzle, respectively

bifurcated nozzle are smaller than those for the straight nozzle.

In the continuous castings of steel, the secondary dendrite arm spacing is closely related with the local solidification time (or the mean cooling rate). ${ }^{24)}$ Therefore, the local solidification time in the slab can be estimated from the secondary dendrite arm spacings observed after freezing. The secondary dendrite arm spacings in the practical operations of the continuous castings of steel $^{7,25-27)}$ showed that the values of $\theta_{f}$ increase monotonously from the slab surface to some distance, but in the range near the center of slab the values of $\theta_{f}$ are kept constant or decrease. However, in the results observed by the use of $\mathrm{KCl}$ solution shown in Fig. 10, the values of $\theta_{f}$ increase 


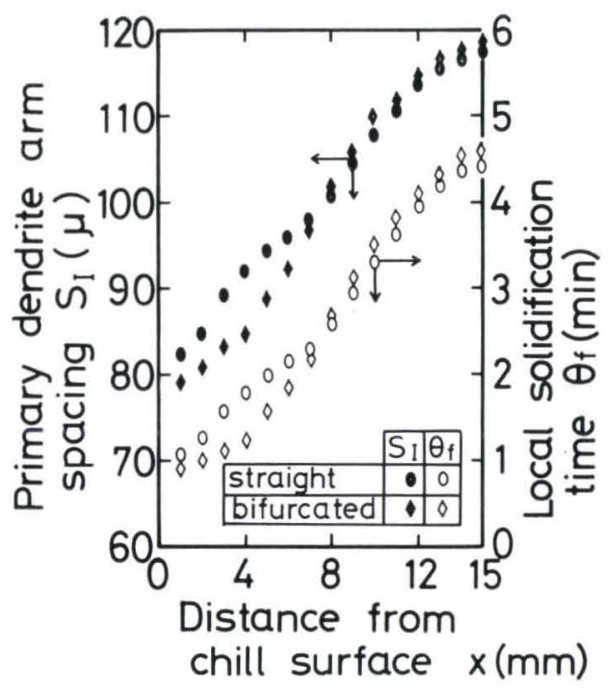

Fig. 10. Observed data of the local solidification time and estimated data of the primary dendrite arm spacings for each case of straight nozzle and bifurcated nozzle

monotonously with the distance from the slab surface to the center of slab. In the case of the continuous castings of steel, the location at which the values of $\theta_{\text {f }}$ begin to become constant or to decrease with the increase in the distance changes with the teeming temperature and the cooling conditions on the slab surface. ${ }^{25,26)}$ This difference concerning $\theta_{\text {, between }}$ this model experiment and the continuous castings of steel would be due to the fact that in the aqueous solution of KCl the dendritic solidification proceeds all over the zone from the surface to the center of slab and on the other hand the equiaxed crystals are formed at the center region in the case of the continuous casting of steel.

\section{Comparisons between Calculated Results and Observed Data}

The solidification profiles and the temperature distributions calculated with the aid of the present authors' model') have been compared with the experimental data obtained in this study. The data adopted for the numerical computations are shown in Table 2. It can be assumed that the physical properties of the solid being formed with the freezing of the dilute solution of $\mathrm{KCl}$ are almost similar to those of ice. The values of the specific heat, the thermal conductivity and the density given in Table 2, therefore, are the approximate figures averaged between the solution of $\mathrm{KCl}$ of $1 \mathrm{~mol} / l$ and ice. By adopting $\Delta H_{\mathrm{e}}=71 \mathrm{cal} / \mathrm{g}^{22)}$ as the value of the latent heat of solidification for the $\mathrm{KCl}$ solution of the eutectic concentration, the latent heat given in Table 2 is estimated on the basis of Eq. (1).

The comparisons of the calculated solidification profiles with the experimental data obtained by using the straight nozzle are shown in Fig. 11. The good agreement between the calculated results and the observed data is obtained in Fig. 11 except the lower part of the solidus line for the case of the casting speed of $6.9 \mathrm{~cm} / \mathrm{min}$. It may be considered that
Table 2. Data for calculations

$$
\begin{array}{ll}
c=0.75 \mathrm{cal} / \mathrm{g} \cdot{ }^{\circ} \mathrm{C} & k=0.0035 \mathrm{cal} / \mathrm{cm} \cdot \mathrm{sec} \cdot{ }^{\circ} \mathrm{C} \\
\rho=0.95 \mathrm{~g} / \mathrm{cm}^{3} & \lambda=77.3 \mathrm{cal} / \mathrm{g} \\
t_{0}=6{ }^{\circ} \mathrm{C} & t_{l}=-3.25^{\circ} \mathrm{C} \\
t_{s}=-10.7^{\circ} \mathrm{C} & t_{w}=-60^{\circ} \mathrm{C} \\
h_{1}=0.003 \mathrm{cal} / \mathrm{cm}^{2} \cdot \sec \cdot{ }^{\circ} \mathrm{C} & h_{2}=0.0015 \mathrm{cal} / \mathrm{cm}^{2} \cdot \mathrm{sec} \cdot{ }^{\circ} \mathrm{C}
\end{array}
$$

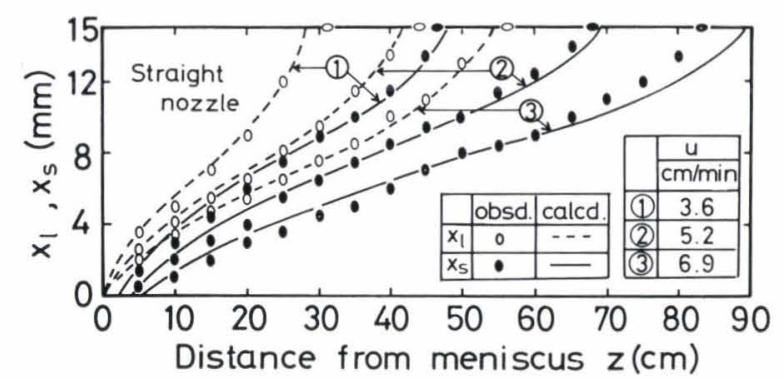

Fig. 11. Comparison of the calculated solidification profiles with the observed ones

this disagreement resulted from the unsteady state conditions. In these calculations, the over-all heat transfer coefficient $\left(h_{1}\right)$ was kept constant for the withdrawal direction. It is expected that the value of the heat transfer coefficient $\left(h_{2}\right)$ on the solidification front in the forced-convection region of liquid pool differs from the one in the lower part of the pool. However, for the case of the freezing of the $\mathrm{KCl}$ solution, the calculated results are affected significantly by the selected values of the physical properties such as the specific heat and the thermal conductivity. Thus, for the sake of simplification, the value of $h_{2}$ was also kept constant for the withdrawal direction. However, Fig. 11 shows that the profiles of the liquidus line calculated by using the constant value of $h_{2}$ agree well with the observed data except the zone near the end point of liquidus line.

For the case of the straight nozzle, the calculated temperature distributions are compared with the observed data in Fig. 12. From Fig. 12, it is found that the tendencies of both results are in approximate agreement, but that the differences between both results increase with the progress of the freezing. It may be considered that these disagreements originated mainly from assuming the same values of the thermal properties in the solid and liquid phases. The approximation as to the temperature distributions in solid shell and in the mushy zone by the quadratic curve with the aid of the integral-profile methods may not cause a serious error.

\section{Similarity Relevant to Heat Transfer}

Jackson, et al. ${ }^{8,9)}$ classified the morphology of crystal growth on the solidification interface by the use of the simple model based on the statistical mechanics and reported several transparent organic compounds which are similar to metals in the morphology of crystal growth. On investigating the solidification profiles by means of a model experiment using the transparent compounds mentioned above, it is desir- 


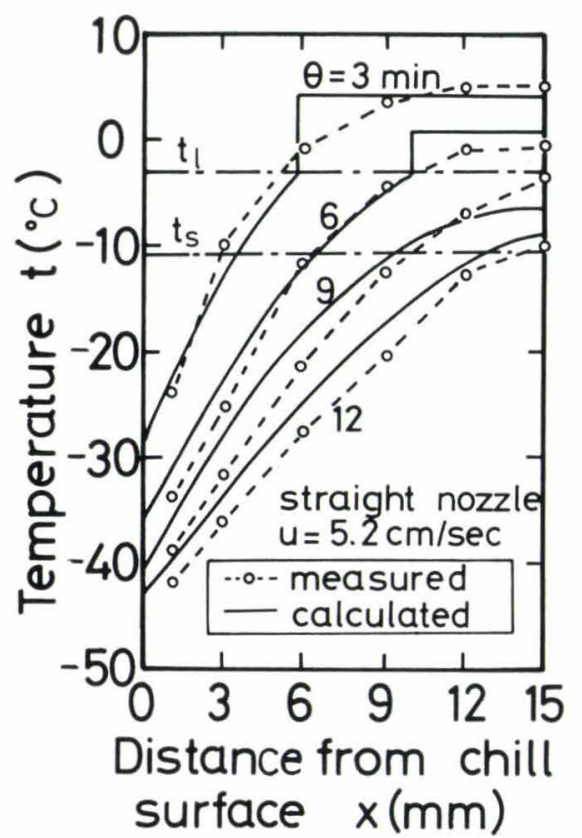

Fig. 12. Comparison of the calculated temperature profiles with the measured ones

able to examine the quantitative similarity of heat transfer between the model system and the practical system of the freezing steel.

The equations of heat balance and the boundary conditions in the mathematical model of vertical type continuous casting machines proposed by the authors $^{2)}$ can be rewritten to the nondimentional form by using the dimensionless variables expressed by Eq. (4). Thus, the resultant equations can be presented in terms of the dimensionless parameters in Eq. (5).

$$
\begin{aligned}
& T=\left(t-t_{s}\right) /\left(t_{l}-t_{s}\right), \quad X=x / W, \Theta=k z / \rho c u W^{2} \\
& H=\lambda / c\left(t_{l}-t_{s}\right), \quad \mathcal{N}_{1}=h_{1} W / k, \quad \mathcal{N}_{2}=h_{2} W / k, \\
& T_{0}=\left(t_{0}-t_{s}\right) /\left(t_{l}-t_{s}\right), \quad T_{w}=\left(t_{w}-t_{s}\right) /\left(t_{l}-t_{s}\right) \ldots \ldots
\end{aligned}
$$

In Eq. (5), $T_{0}$ designates the dimensionless teeming temperature and $T_{w}$ denotes the dimensionless coolant temperature, and these temperatures depend on the operating conditions alone. $H$ is related only to the physical properties of the solidification system. $\mathcal{N}_{1}$ and $\mathcal{N}_{2}$ include $h_{1}$ and $h_{2}$, respectively, and depend on both the physical and the operating conditions.

The changes in the solidification thickness $\left(X_{l}\right.$, $X_{s}$ ) and the temperature $(T)$ with the dimensionless time $(\Theta)$ are definitely affected by the five parameters mentioned above. Hence, by selecting experimental conditions to have the agreement of the parameters in the model experiment with those in the practical continuous casting of steel, the transitional changes of $X_{l}, X_{s}$ and $T$ become similar between both cases. Here, the similar conditions in the practical operation have been estimated by focusing on the parameter $(H)$ which has the marked effects on the solidification profiles.

The values of $\mathrm{H}$ in each system of $\mathrm{KCl}-\mathrm{H}_{2} \mathrm{O}$ and $\mathrm{NH}_{4} \mathrm{Cl}-\mathrm{H}_{2} \mathrm{O}$ are shown in Fig. 13. These values

\begin{tabular}{|c|c|c|c|c|}
\hline & $\mathrm{C}$ & $\lambda$ & $\Delta \mathrm{He}$ & $\Delta \mathrm{Hc}$ \\
\cline { 2 - 5 } & $\mathrm{cal} / \mathrm{g} \cdot \mathrm{C}$ & $\mathrm{cal} / \mathrm{g}$ & $\mathrm{cal} / \mathrm{g}$ & $\mathrm{cal} / \mathrm{g}$ \\
\hline $\mathrm{KCl}-\mathrm{H}_{2} \mathrm{O}$ & 0.75 & Eqs. (1),(2) & $71^{22)}$ & $59^{29)}$ \\
\hline $\mathrm{NH}_{4} \mathrm{Cl}-\mathrm{H}_{2} \mathrm{O}$ & 0.75 & Eqs (1),(2) & $75^{22}$ & $71^{29)}$ \\
\hline $\mathrm{Fe}-\mathrm{C}$ & 0.16 & 65 & - & - \\
\hline
\end{tabular}

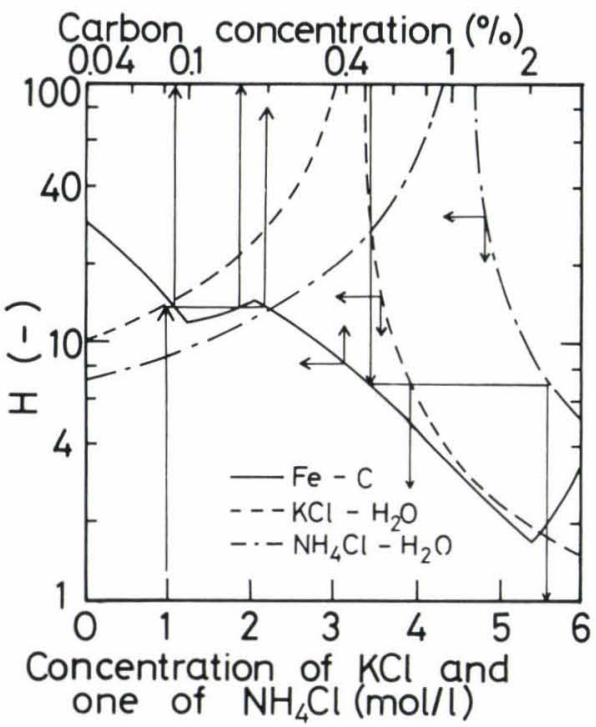

Fig. 13. Variations of the nondimensional parameter $H$ for $\mathrm{KCl}-\mathrm{H}_{2} \mathrm{O}, \mathrm{NH}_{4} \mathrm{Cl}-\mathrm{H}_{2} \mathrm{O}$ and $\mathrm{Fe}-\mathrm{C}$ systems, respectively

were calculated by using the values of $\lambda$ estimated by substituting the data given in the upper part of Fig. 13 into Eqs. (1) and (2) and also the values of $\left(t_{l}-t_{s}\right)$ obtained from the phase diagram illustrated in Fig. 2. Here, the heats of crystallization $\left(\Delta H_{\mathrm{c}}\right)$ in the region of higher concentration than the eutectic one were estimated in accordance with Mullin's way. ${ }^{28)}$ Since the latent heat of solidification does not change very much with the concentration, the large changes of $H$ found in Fig. 13 are due to the changes of $\left(t_{l}-\right.$ $\left.t_{s}\right)$ with the concentration. The relation between $H$ and the carbon concentration in $\mathrm{Fe}-\mathrm{C}$ system is also shown in Fig. 13. In the calculations for determining this relation, the latent heat of solidification and the specific heat for the $\mathrm{Fe}-\mathrm{C}$ system were kept constant regardless of the change of the carbon concentration. With respect to the heat transfer alone, Fig. 13 suggests that the solidification of the $\mathrm{KCl}$ solution of $1 \mathrm{~mol} / l$ corresponds to that of steel having the concentration of $0.09,0.16$ and $0.2 \%$ carbon. On the other hand, when a model experiment is planned for more than $0.5 \%$ carbon steel, the solution of the higher concentration than the eutectic one using either $\mathrm{KCl}-\mathrm{H}_{2} \mathrm{O}$ system or $\mathrm{NH}_{4} \mathrm{Cl}-\mathrm{H}_{2} \mathrm{O}$ system has to be used (cf. the arrows shown in Fig. 13).

In this model experiment, $T_{0}\left(=\left(t_{0}-t_{s}\right) /\left(t_{l}-t_{s}\right)\right)$ becomes equal to 2.2 , since $t_{l}=-3.25^{\circ} \mathrm{C}, t_{s}=$ $-10.7^{\circ} \mathrm{C}$ and $t_{0}=6^{\circ} \mathrm{C}$ were adopted. Thus, in the case of the continuous casting of steel of $0.2 \%$ carbon $\left(t_{l}=\right.$ $1520^{\circ} \mathrm{C}, t_{s}=1490^{\circ} \mathrm{C}$ ), the teeming temperature of $1550^{\circ} \mathrm{C}$ has to be chosen in order to have the same values of $T_{0}$ for both cases. Hence, the teeming condition used in this experiment corresponds to the practical casting condition of molten steel with the 
superheat of about $35^{\circ} \mathrm{C}$.

\section{Conclusions}

The model experiments on the $\mathrm{KCl}$ solution for the continuous casting of slab gave the solidification profiles from the meniscus to the bottom of the mushy zone, the temperature distributions in the slab and the depth of penetration of the inlet stream for the straight and bifurcated nozzles.

Under the experimental conditions of this study, the solidification profile changes significantly with the change of the casting speed alone. When a same nozzle has been used, the changes of the solidification thickness with the progress of the solidification time are almost the same regardless of the casting speed. The area of the region of forced convection caused by the inlet stream, the degree of mixing and the temperature distributions in the liquid pool are different between the straight and bifurcated nozzles due to the differences in the flow pattern in the liquid pool. As the results, it has been found that the profiles of liquidus line corresponding to the region of forced convection are different each other, but the notable differences in the profiles of solidus line cannot be recognized regardless of the nozzle types.

The primary dendrite arm spacings were estimated from the local solidification time obtained in this model experiment. The spacings in each location from the slab surface are somewhat different with the nozzle type in the region of the forced convection.

Furthermore, the solidification profiles and the temperature distributions observed in this study have been compared with those calculated on the basis of the mathematical model presented by the authors. As the results, the close agreement between the observed and calculated values of the solidification profiles has been obtained regardless of the large changes in the physical properties with the progress of freezing of the $\mathrm{KCl}$ solution.

\section{Nomenclature}

$a, b:$ constant $(\mu / \mathrm{cm}),(\mu)$

$c:$ specific heat $\left(\mathrm{cal} / \mathrm{g} \cdot{ }^{\circ} \mathrm{C}\right)$

$C_{0}$ : initial concentration $\left(\mathrm{wt}^{\mathrm{o}} \%\right.$ )

$C_{\mathrm{e}}$ : eutectic concentration $(w \mathrm{t} \%)$

$f$ : solid fraction $(-)$

$\bar{f}$ : mean solid fraction $(-)$

$H$ : dimensionless parameter defined by Eq. (5) $(-)$

$\Delta H_{\mathrm{c}}$ : heat of crystallization $(\mathrm{cal} / \mathrm{g})$

$\Delta H_{\mathrm{e}}$ : latent heat of solidification of eutectic solution (cal $/ \mathrm{g}$ )

$\Delta H_{\mathrm{w}}$ : latent heat of solidification of water (cal $/ \mathrm{g}$ )

$h_{1}$ : over-all heat transfer coefficinet based on the temperature difference between outer surface of slab and coolant $\left(\mathrm{cal} / \mathrm{cm}^{2} \cdot \sec \cdot{ }^{\circ} \mathrm{C}\right)$

$h_{2}$ : heat transfer coefficient on the surface of solidification front $\left(\mathrm{cal} / \mathrm{cm}^{2} \cdot \mathrm{sec} \cdot{ }^{\circ} \mathrm{C}\right)$

$K$ : solidification constant $\left(\mathrm{cm} / \mathrm{sec}^{1 / 2}\right)$

$k$ : thermal conductivity $\left(\mathrm{cal} / \mathrm{cm} \cdot \mathrm{sec} \cdot{ }^{\circ} \mathrm{C}\right)$

$\mathcal{N}$ : Nusselt number $(-)$

$S_{I}$ : primary dendrite arm spacing $(\mu)$ t, T: temperature $\left({ }^{\circ} \mathrm{C}\right),(-)$

$u$ : casting speed $(\mathrm{cm} / \mathrm{sec})$

$W:$ half thickness of slab $(\mathrm{cm})$

$x, X$ : distance from slab surface $(\mathrm{cm}),(-)$

$z$ : distance from meniscus $(\mathrm{cm})$

$z_{l}, z_{s}$ : ends of liquidus and solidus lines $(\mathrm{cm})$

$\alpha:$ thermal diffusivity $\left(\mathrm{cm}^{2} / \mathrm{sec}\right)$

$\theta, \Theta:$ solidification time (sec), $(-)$

$\theta_{f}:$ local solidification time $(\mathrm{sec})$

$\lambda$ : latent heat of solidification $(\mathrm{cal} / \mathrm{g})$

$\rho:$ density $\left(\mathrm{g} / \mathrm{cm}^{3}\right)$

\section{Subscripts}

$c s$ : surface of mold

$d$ : depth of penetration of inlet stream

$l$ : liquidus line

s: solidus line

w: coolant

0 : inlet of mold

1: solid shell

2: mushy zone

\section{REFERENCES}

1) H. Ooi and J. Matsuno: Tetsu-to-Hagané, 60 (1974), 807.

2) K. Miyazawa and I. Muchi: Trans. ISIJ, 15 (1975), 37.

3) S. Asai and J. Szekely: Ironmaking and Steelmaking, 2 (1975), 205.

4) K. Ushijima: The 4th Nishiyama Memorial Technical Lecture, ISIJ, (1969), 107.

5) S. N. Singh and K. E. Blazek: J. Metals, 26 (1974), No 10,17 .

6) J. E. Lait, J. K. Brimacombe and F. Weinberg: Ironmaking and Steelmaking, $\mathbf{1}$ (1974), 35.

7) T. Kawawa, H. Sato, S. Miyahara, T. Koyano and H. Nemoto: Tetsu-to-Hagané, 60 (1974), 206.

8) K. A. Jackson and J. D. Hunt: Acta Met., 13 (1965), 1212.

9) K. A. Jackson, D. R. Uhlmann and J. D. Hunt: J. Crystal Growth, 1 (1967), 1.

10) P. K. Rohatgi and C. M. Adams: Trans. Met. Soc. AIME, 239 (1967), 850.

11) T. Okamoto, K. Kishitake and I. Bessho: Report of the 19th Comm. of Japan Society for the Promotion of Science, Solidification, No. 9369, (1972).

12) L. J. Thomas and J. W. Westwater: Chem. Eng. Prog., 59 (1963), Symp. Series, No. 41, 155

13) D. V. Boger and J. W. Westwater: Trans, ASME, Series C, 89 (1967), 81.

14) K. A. Jackson, J. D. Hunt, D. R. Uhlmann and T. P. Seward: Trans. Met. Soc. AIME, 236 (1966), 149.

15) A. Ohno: The Solidification of Metals, No. 110, ISI, (1968), 349.

16) W. M.J. Salter and P. E. Wandly: The Solidification of Metals, No. 110, ISI, (1968), 412.

17) R. J. McDonald and J. D. Hunt: Trans. Met. Soc. AIME, 245 (1969), 1993.

18) P. M. Thomas and J. A. Spittle: J. Inst. Metals, 99 (1971), 167.

19) I. G. Davies and A. M. Timmins: Iron and Steel Internl., 47 (1974), 39.

20) N. T. Mills and L. F. Barnhardt: J. Metals, 23 (1971), No. 11, 37.

21) S. Watanabe, K. Harada and J. Fujita: Tetsu-to-Hagané, 58 (1972), S393

22) E. W. Washburn, C. J. West and N. E. Dorsey: International Critical Tables, I, McGraw-Hill, (1926), 63; IV, 
(1928), 218, 239, 255 and 259.

23) S. T. Bowden: The Phase Rule and Phase Reactions, Macmillan, (1938), 221.

24) T. Okamoto: Tetsu-to-Hagané, 58 (1972), 1302.

25) A. Suzuki, T. Suzuki and T. Nozaki: Tetsu-to-Hagané, $\mathbf{5 6}$ (1970), S272.

26) H. Kumai, K. Asano, T. Ohashi, E. Nomura and H. Fujii: Tetsu-to-Hagané, 60 (1974), 894.

27) T. Fujii, J. Matsuno and H. Ooi: Tetsu-to-Hagané, 60 (1974), 1041.

28) J. W. Mullin: Crystallization, Butterworths, (1961), 62.

29) R.H. Perry, C. H. Chilton and S. D. Kirkpatrick: Chemical Engineers' Handbook, III, 4th ed., McGrawHill, (1963), 144, 145.

\section{Appendix}

Rohatgi and Adams ${ }^{10)}$ adopted such experimental conditions as no superheats in the liquid pool and the constant temperature on the mold surface. Thus, assuming the constant physical properties in a solid shell and a mushy zone, and taking the heat balances around the both regions, Eqs. (A-1) and (A-2) can be obtained.

$$
\begin{aligned}
& \partial t_{1} / \partial \theta=\alpha\left(\partial^{2} t_{1} / \partial x^{2}\right) \quad \ldots \ldots \ldots \ldots \ldots \ldots \ldots \ldots \ldots \ldots \ldots \ldots \\
& \partial t_{2} / \partial \theta=\alpha\left(\partial^{2} t_{2} / \partial x^{2}\right)+\left(\Delta H_{\mathrm{w}} / c\right) \cdot(\partial f / \partial \theta)
\end{aligned}
$$

where, $f$ designates a solid fraction and it is represented by Eq. (A-3) as a function of temperature according to the phase diagram.

$$
f=\left(t_{l}-t\right) /\left\{\left(t_{s}-t\right)+\left(t_{l}-t_{x}\right) f^{*}\right\} .
$$

where, $f *$ denotes the solid fraction when the temperature of mushy zone has become equal to the solidus temperature, and for the $\mathrm{KCl}$ solution of $1 \mathrm{~mol} / l$, the value of $f *\left(\left(=C_{\mathrm{e}}-C_{0}\right) / C_{\mathrm{e}}\right)$ becomes equal to 0.7 . Thus, at the solidus line the latent heat of solidification being expressed by $\left(1-f^{*}\right) \cdot \Delta H_{\mathrm{o}}$ may be released per unit mass.

The boundary conditions at the mold surface, the solidus line and the liquidus line are given by Eqs. (A-4) to (A-6), respectively.

$$
\begin{aligned}
& t_{1}=t_{c s} \quad \text { at } x=0 \\
& t_{1}=t_{2}=t_{s} \text {, } \\
& k\left(\partial t_{1} / \partial x\right)=k\left(\partial t_{2} / \partial x\right)+\rho\left(1-f^{*}\right) \cdot \Delta H_{\mathrm{e}}\left(d x_{s} / d \theta\right) \\
& \text { at } x=x_{s} \\
& t_{2}=t_{l}, \quad \partial t_{2} / \partial x=0 \quad \text { at } x=x_{\iota} .
\end{aligned}
$$

Postulating the temperature distributions in the solid shell and the mushy zone as a quadratic function of $x$ and solving Eqs. (A-1) and (A-2) with the aid of an integral profile method, the changes in the solidification thickness with the progress of the solidification time can be expressed by Eqs. (A-7) and (A-8).

$$
\begin{aligned}
& x_{s}=K_{s} \sqrt{ } \theta \\
& x_{l}=K_{l} \sqrt{ } \theta
\end{aligned}
$$

where, $K_{s}$ and $K_{l}$ designate the solidification con- stants and both can be obtained by solving Eqs. (A9) and (A-10) simultaneously.

$$
\begin{aligned}
& 12 \alpha-K_{s}^{2} \quad t_{s}-t_{c s} \quad K_{s}\left(1-f^{*}\right) \cdot \Delta H_{\mathrm{e}} \\
& K_{s}\left(K_{s}^{2}+24 \alpha\right) \cdot t_{l}-t_{s}-4 c\left(t_{l}-t_{s}\right) \\
& =\frac{1}{K_{l}-K_{s}} \\
& {\left[\frac{1}{3}+\begin{array}{c}
\Delta H_{\mathrm{w}} \cdot \bar{f} \\
c\left(t_{l}-t_{s}\right)
\end{array}\right] \cdot\left(K_{l}-K_{s}\right)+\left[1+\frac{\Delta H_{\mathrm{w}} \cdot f^{*}}{c\left(t_{l}-t_{s}\right)}\right] K_{s}} \\
& =\begin{array}{c}
4 \alpha \\
K_{l}-K_{s}
\end{array}
\end{aligned}
$$

In Eq. (A-10), $\bar{f}$ denotes the mean value of the solid fraction in the mushy zone and provided that the solid fraction can be expressed by Eq. (A-3), $\bar{f}$ is presented by Eq. (A-11).

$$
\bar{f}=\left[\int_{x_{s}}^{x_{l}} f d x\right] /\left(x_{l}-x_{s}\right)=1-0.785 \sqrt{ }\left(1-f^{*}\right) / f^{*}
$$

Hence, by using Eqs. (A-7) and (A-8), the local solidification time at the distance of $x$ from the mold surface can be shown by Eq. (A-12).

$$
\theta_{f}=\left(1 / K_{s}^{2}-1 / K_{l}^{2}\right) x^{2}
$$

According to the results observed by Rohatgi and Adams $^{10)}$ on the other hand, the primary dendrite arm spacings increase with the distance from the mold surface and the relations between them are expressed by $S_{I}=a x+b$ (where, $a$ and $b$ are constants). Therefore, the relation between the primary dendrite arm spacing and the local solidification time can be represented by Eq. (A-13).

$$
S_{I}=\left(a / \sqrt{ } 1 / K_{s}^{2}-1 / K_{l}^{2}\right) \sqrt{ } \theta_{f}+b \ldots \ldots \ldots(\mathrm{A}
$$

Here, by using the results observed by Rohatgi and Adams, $a=37.5 \mu / \mathrm{cm}$ and $b=48 \mu$ are obtained for the $\mathrm{KCl}$ solution of $1 \mathrm{~mol} / l$. It is common to obtain $K_{s}$ and $K_{l}$ by substituting the values of the physical properties and the temperature on the mold surface into Eqs. (A-9) and (A-10). However, since the value of the solidification constant of solidus line $\left(K_{s}=0.6 \mathrm{~cm} / \mathrm{min}^{1 / 2}\right)$ can be obtained from the results observed by Rohatgi and Adams and for the reason that the physical properties in the solid shell and the mushy zone were kept constant in this analysis, $K_{l}$ and $\alpha$ were considered as the unknown quantities and the trial and error method was applied to determining them in this study.

Thus, the values of $K_{l}=0.82 \mathrm{~cm} / \mathrm{min}^{1 / 2}$ and $\alpha=$ $0.0069 \mathrm{~cm}^{2} / \mathrm{sec}$ were obtained from the results calculated by the use of the values such as $t_{l}=-3.25^{\circ} \mathrm{C}$, $t_{s}=-10.7^{\circ} \mathrm{C}, t_{c s}=-70^{\circ} \mathrm{C}, \quad f^{*}=0.7, \Delta H_{\mathrm{w}}=80 \mathrm{cal} / \mathrm{g}$, $\Delta H_{\mathrm{e}}=71 \mathrm{cal} / \mathrm{g}$ and $c=0.75 \mathrm{cal} / \mathrm{g} \cdot{ }^{\circ} \mathrm{C}$. This value of $\alpha$ may be approximately considered as the mean value of the thermal diffusivities between the $\mathrm{KCl}$ solution and the ice. Equation (3) can be obtained by substituting the values of $K_{s}, K_{l}, a$ and $b$ described above into Eq. (A-13). 